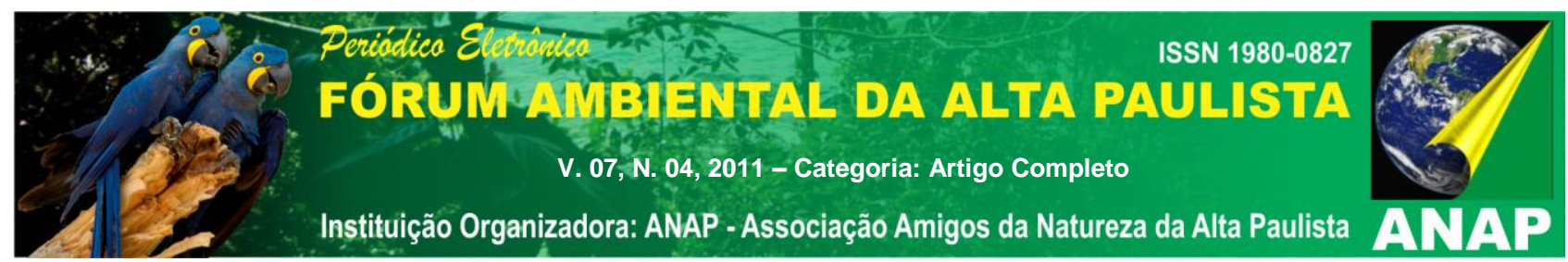

\title{
SUSTENTABILIDADE NO MEIO URBANO
}

\section{Regina Célia Foschini ${ }^{1}$}

RESUMO: Hoje as cidades se encontram em trágica situação, como crescimento urbano desarticulado, resíduos urbanos, aumento de densidade populacional, degradação ambiental, etc. Partindo do conceito de desenvolvimento sustentável e das críticas sobre os desastrosos efeitos dos processos de urbanização ocorridos no planeta nos últimos trinta anos, esse texto iniciou-se com levantamento bibliográfico para apreensão dos conceitos e diretrizes que fundamentam a sustentabilidade no meio urbano e utilizando-se metodologia de modo dialético foi possível refletir sobre a introdução do conceito de sustentabilidade no planejamento dos espaços urbanos, finalizando a pesquisa.

Palavras chave: Sustentabilidade. Desenvolvimento sustentável. Meio urbano.

\section{1 - INTRODUÇÃO}

A definição de desenvolvimento sustentável foi controversa e variou ao longo do tempo, em diferentes culturas e classes sociais. Nos últimos anos, a difusão de informações sobre densidade social, pobreza e uso indiscriminado dos recursos naturais implementaram discussões sobre o modelo de desenvolvimento convencionais, via de regra exacerbadores dos problemas sociais da humanidade, incluindo a degradação ambiental e conseqüente perda da biodiversidade (BORGES, 2004:357).

O termo desenvolvimento sustentável é fruto do anseio crescente de parte da sociedade por formas alternativas para o desenvolvimento humano, que contemplem critérios para o uso racional do patrimônio natural e não gerem desigualdades sociais.

Esse novo conceito surgiu do desgaste dos modelos vigentes de desenvolvimento ao longo dos anos, e teve por base contestar os padrões convencionais, visando um enquandramento mais aceitável do que verdadeiramente venha ser desenvolvimento.

No entanto, pelo fato das cidades serem meios complexos, cheios de conflitos e que necessitam constantemente de recursos para satisfazer as necessidades da sua

\footnotetext{
1 Advogada, mestre em Engenharia Urbana pela Universidade Federal de São Carlos. E-mail: reginafos@yahoo.com.br
} 


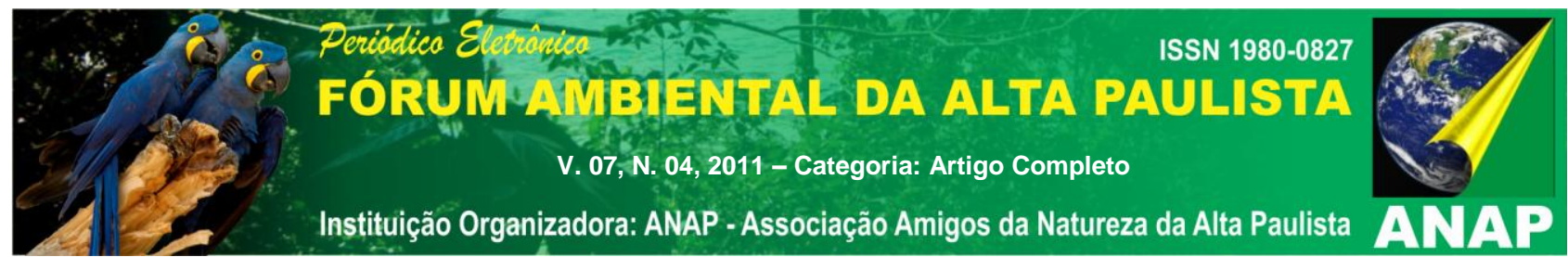

população, seu crescimento acelerado tem se mostrado um fenômeno problemático e de difícil planejamento. Então, requer, para a incorporação de conceitos de desenvolvimento sustentável, "ações no sentido da preservação do meio físico, da qualidade dos elementos naturais com que interage, da priorização da satisfação das necessidades da população que nela habita e também da dignidade social que a sustenta" (VIANNA, 2002).

Diante dessas considerações, buscou-se no presente trabalho abordar e refletir sobre a introdução do conceito de sustentabilidade no planejamento dos espaços urbanos.

\section{2 - SUSTENTABILIDADE}

\subsection{EVOLUÇÃO HISTÓRICA E CONCEITO}

O ser humano sempre utilizou os recursos naturais em seu benefício: água, madeira, frutas e outros alimentos extraídos das matas, minerais, o próprio ar pareciam bens inesgotáveis e acessíveis a toda e qualquer pessoa.

Antes da civilização moderna, a natureza era considerada uma força superior que se devia respeitar, e as reflexões feitas a seu respeito consideravam a ação humana "humilde e dominada por seus ciclos". Já na tradição ocidental, o pensamento clássico grego sustentava que "os Deuses haviam disposto tudo em benefício do homem", surgindo então uma ruptura substancial entre o homem e a natureza (FOLADORI, 2001).

Essas idéias de domínio do homem sobre a natureza foram sistematizadas pelo judaísmo e pelo cristianismo, e o ser humano passou a aparecer "como um intermediário entre Deus e o restante do mundo natural, para ordená-lo e dominá-lo", apesar de sempre surgir pensamentos opostos, da "harmonia com a natureza", como abordado por Maimônides (1135-1204) e por Francisco de Assis (1182-1226), na Idade Média (FOLADORI, 2001).

Com a Idade Moderna (séculos XVII e XVIII), o impacto mais importante foi a conquista do mundo pelo capital mercantil, que passou a ver a natureza como um somatório de partes possível de ser explorado de forma crescente. 


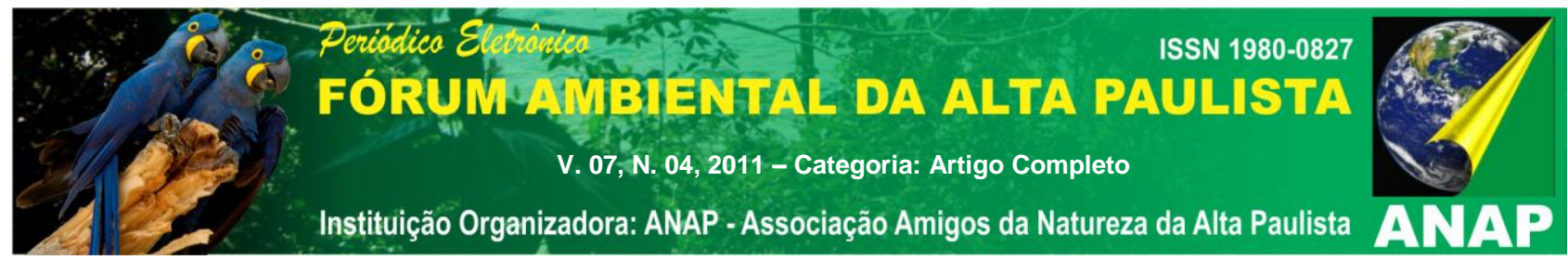

Foladori (2001) aduz que a Revolução Industrial do século XVIII, com a revolução dos transportes e comunicações do último quarto do século XIX, "permitiu a expansão imperialista, colonização e conquista completa do mundo, provocando um ponto de inflexão na relação do ser humano com a natureza". Nessa época, o crescimento econômico era o principal objetivo das nações do mundo.

Os abusos cometidos contra a natureza, que começaram com a Revolução Industrial, tiveram como fator complicador o aumento populacional (PELLEGRINI,1993) e, dentro dessa ideologia econômica tradicional, relacionava-se o processo técnico com a evolução humana, pois "acreditava-se que as soluções tecnológicas resolveriam qualquer problema e defendia-se que o crescimento quantitativo das economias seria capaz de gerar as riquezas necessárias para erradicar a pobreza" (MILANEZ E TEIXEIRA, 2001).

No entanto, o crescimento do capitalismo produziu efeitos sobre a própria espécie humana, pois se criou uma população excedente à produção, e novas formas de exploração do trabalho. Ao lado da destruição dos povos pré-capitalistas, com a exploração maciça de milhares de assalariados da indústria nascente, a destruição da natureza aumentava. Centenas e milhares de animais foram caçados, outros desapareceram devido à transformação de seus habitats. Florestas foram destruídas e as madeiras utilizadas pela urbanização e indústria naval.

Surgiram, então, movimentos conservacionistas e românticos em defesa do meio ambiente, que reivindicavam uma natureza virgem e intocada, mas se esqueciam de que os povos subjugados e as classes exploradas e oprimidas faziam parte do ambiente; e movimentos socialistas, que criticavam o modo capitalista de produção que acentuava os prejuízos para a própria espécie humana.

Os primeiros a relacionar as contradições entre as classes sociais e o meio ambiente foram Marx (1818-1883) e Engels (1820-1895).

Tanto Marx como Engels (apud FOLADORI, 2001) argumentavam que

Eram as contradições de classes que obrigavam o capital a se expandir, saqueando o mundo. Assim, sua concepção não era simplesmente antropocêntrica, no sentido de que ao ser humano interessa a natureza como meio de vida, mas, sobretudo classista. É a burguesia a interessada na natureza exclusivamente como fonte de matéria-prima, para que o trabalho assalariado possa ser explorado. O interesse da burguesia como classe não é a natureza como meio de vida, mas à medida que esta possibilite o aumento da taxa de exploração do trabalho assalariado, quer dizer, a geração do lucro, embora como pessoas defendam o meio ambiente. 


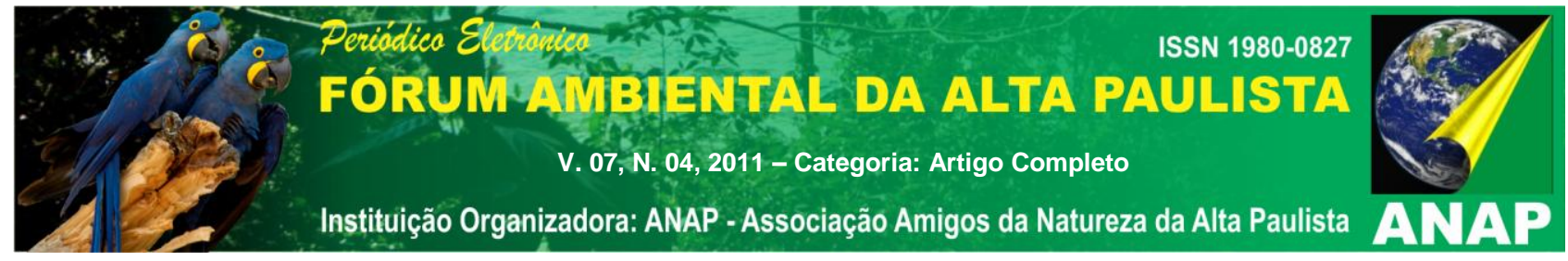

Marx e Engels pensavam o mundo de forma dialética, ou seja, analisavam a totalidade como movimento contraditório, o que implicava atenção tanto ao progresso como ao retrocesso. No mais, Marx e Engels por várias vezes advertiram sobre a "vingança que a natureza infringia à sociedade humana como resposta à devastação produtiva" (apud FOLADORI, 2001).

No último quarto do século XIX, surge a revolução neoclássica como reação à crítica que o marxismo fazia do sistema capitalista, visando a distribuição dos recursos escassos para a satisfação das necessidades, e não mais o estudo da produção ou da geração de riquezas. Assim, as inúmeras crises econômicas deste século vieram advertindo aos pensadores que o mercado não era o melhor alocador de recursos.

Foladori (2001) ressalta que a Primeira Guerra Mundial "foi a demonstração empírica mais contundente de que o mercado não era sequer o principal elemento na alocação de recursos". No entanto, foi a bomba atômica detonada pelos norte-americanos em Hiroshima em 1945, durante a Segunda Guerra Mundial, o "novo marco, ao se constituir na demonstração prática e imediata mais nítida das possibilidades de o ser humano modificar a biosfera de maneira radical, tanto em amplitude como em relação a seus efeitos no tempo", e o século XX "torna ainda mais agudas as posições encontradas sobre a relação entre o mundo industrial moderno e a natureza".

A partir de 1960, depois de terem sido dados alguns alertas, a humanidade começou a tomar consciência dos abusos cometidos contra a natureza, em nome do crescimento econômico.

Começaram a surgir preocupações com as condições ambientais negativas que o ser humano impunha sobre o meio em que vivia, sobretudo através de manifestações técnico-científicas. Nessa época, surgiram várias publicações discutindo os efeitos das ações humanas sobre o meio ambiente. Uma delas, Primavera Silenciosa, "enfatizava a ligação existente entre o ser humano e todos os seres vivos com o ambiente físico, mostrando que os processos naturais têm uma capacidade de ação limitada, isto é, uma capacidade que não pode ser ultrapassada pela atividade antrópica" (TEIXEIRA et al., 1998).

No ano de 1971, surgiu o programa da Unesco O Homem e a Biosfera, "que procurou desenvolver pesquisas ecológicas com um caráter interdisciplinar, em que as 


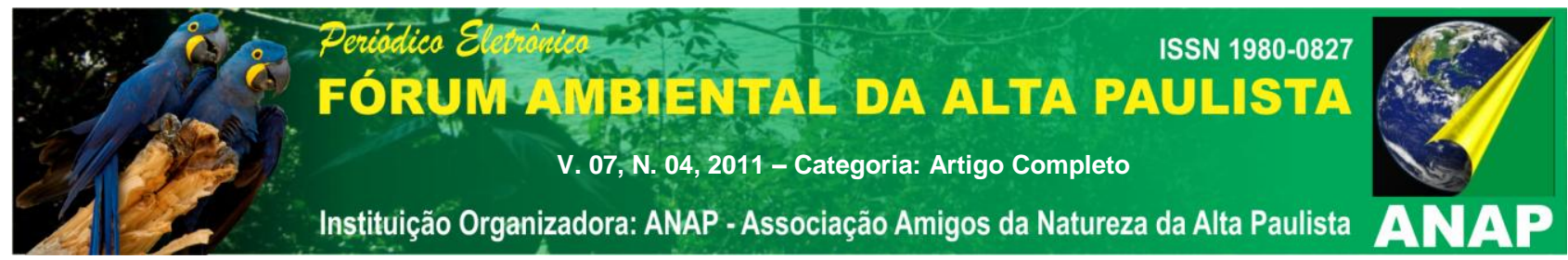

ciências sociais e as naturais tinham igual importância" (VON DROSTE, apud TEIXEIRA et al.,1998), e guiava as atividades sobre um novo conceito, o de "conservação para um desenvolvimento duradouro" (SILVA E TEIXEIRA, 1999).

No ano seguinte, outros dois acontecimentos enfatizaram a questão ambiental. O primeiro foi a publicação do relatório denominado Os Limites do Crescimento, elaborado por um grupo de cientistas do Massachusetts Institute of Technology (M.I.T.), que alertava para o esgotamento de diversos recursos naturais em decorrência de sua exploração desenfreada, de uma catástrofe ambiental planetária se as expectativas de crescimento econômico se mantivessem constantes (HERCULANO apud LIMA E PORTILHO, 2001), e contra "o falso otimismo de que a tecnologia poderia resolver tudo, induzindo variáveis importantes, como o respeito à capacidade de carga da biosfera e a necessidade de um sistema mundial sustentável" (DIEGUES apud VIANNA, 2002). 0 segundo foi a Conferência das Nações Unidas sobre o Meio Ambiente Humano, também conhecida por ECO-72, realizada pela Organização das Nações Unidas (ONU), em Estocolmo (Suécia), que reuniu, pela primeira vez, um número significativo de países para tratar de questões ambientais. Essa conferência foi o primeiro esforço internacional em defesa do meio ambiente, pois "foi resultado da percepção das nações sobre a degradação ambiental causada pelo seu processo de crescimento econômico e progressiva escassez de recursos naturais" (MILARÉ, 2000).

No entanto, segundo Capobianco (apud VIANNA, 2002), este "foi um momento em que se explicitou ( $\mathrm{sic}$ ), de forma contundente, as divergências entre países desenvolvidos e subdesenvolvidos", pois de um lado estavam "os países ricos, industrializados, querendo estabelecer normas internacionais de controle ambiental e restrições ao crescimento; e do outro, países pobres querendo indústrias para se desenvolverem".

Milaré (2000) comenta que alguns países "chegaram a propor a política de crescimento zero, visando a salvar o que não havia sido ainda destruído", mas diversos países do Terceiro Mundo assumiram uma postura contra as restrições ambientais internacionais estabelecidas em Estocolmo. O Brasil, que estava em pleno regime autoritário, "liderou um grupo de países que pregavam tese oposta, a do crescimento a 


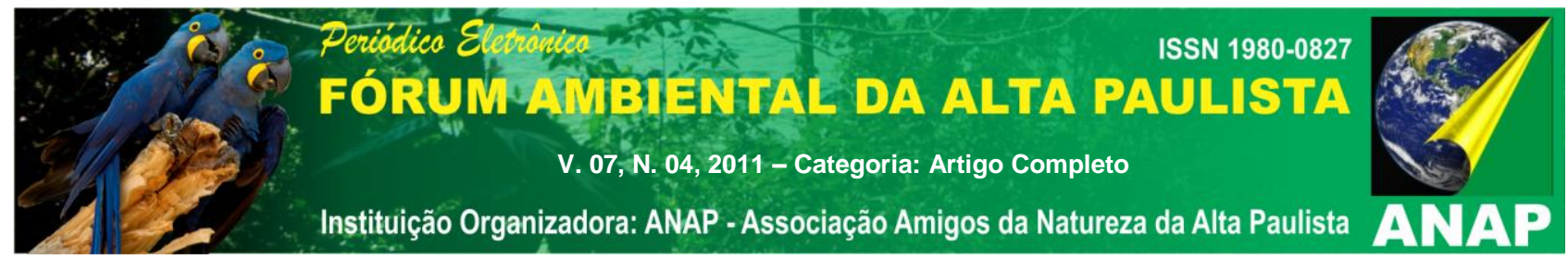

qualquer custo", pois "a poluição e a degradação do meio ambiente eram vistas como um mal menor".

Esses países, segundo Copobianco (apud VIANNA, 2002) "adotaram políticas de desenvolvimento que estavam de portas abertas para receber as indústrias poluentes, que já eram um problema para os países subdesenvolvidos". Nosso país, em tal período, acabou tendo um crescimento econômico elevado, mas por optar em crescer a qualquer custo acabou, impiedosamente, agredindo a natureza, formando uma ferida ainda não estancada.

Assim, a insustentabilidade das sociedades acabou dilapidando os recursos naturais num ritmo muito mais rápido que a capacidade de regeneração, por se apoiarem em um modelo de produção-consumo-descarte. Conseqüentemente, acabou-se afastando da natureza e tal ruptura repercutiu na qualidade de vida da sociedade.

Assim, a possibilidade de se buscar soluções globais para os problemas ecológicos, foi dificultada em função da radicalização entre países desenvolvidos e subdesenvolvidos. Por outro lado, os países desenvolvidos, que possuíam uma legislação ambiental mais rígida, começaram um processo de exportação da degradação ambiental para países subdesenvolvidos. Um exemplo desse processo foi o "chamado milagre brasileiro, ocorrido na década de 70" (COPOBIANCO, apud VIANNA, 2002).

Coimbra (apud MILARÉ, 2000) ressalta:

A sociedade humana, então, percebendo quase instintivamente o caótico da situação, entra em ansiedade difusa. Em seu próprio seio deflagram-se lutas fratricidas, as preocupações materialistas do ter sufocam as preocupações humanistas do ser, as sociedades ricas assumem conduta de prepotência em face das mais carentes. Há sobressaltos de apocalipse e o receio de que esta pequena nave espacial chamada Terra, com todos os seus tripulantes, perca-se naquele tohu abohu assustador, de que fala a Gênesis em seu primeiro enunciado.

Mas, pelo fato de a Conferência de Estocolmo, segundo Sachs (1993), ter transmitido "uma mensagem de esperança sobre a necessidade e a possibilidade de se projetar e implementar estratégias ambientalmente adequadas, para promover um desenvolvimento sócio-econômico eqüitativo", percebeu-se que o modelo de desenvolvimento a qualquer custo estava superado; era preciso mudar, pois a natureza morta não teria serventia para o ser humano. 


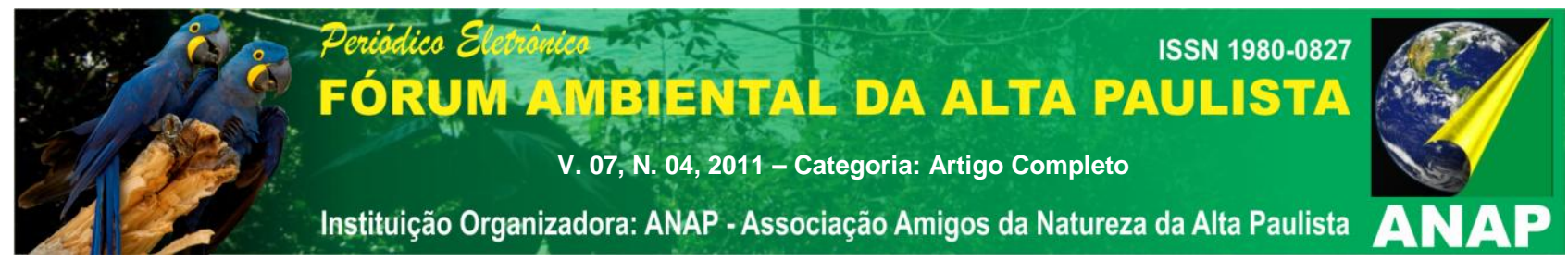

Então, começou neste período uma revisão dos conceitos desenvolvimentistas. Segundo Vianna (2002), "com o trabalho da Fundação Bariloche e da Cepal - Comissão Econômica para a América Latina das Nações Unidas -, que propunham modelos alternativos de desenvolvimento, tanto para países desenvolvidos como para países subdesenvolvidos", salientou-se a importância da conservação do meio ambiente e a renúncia à crença de um desenvolvimento econômico ilimitado. Tais modelos de desenvolvimento receberam adjetivações como Desenvolvimento Alternativo, Ecodesenvolvimento, e posteriormente Desenvolvimento Sustentável. Esses novos conceitos propunham uma nova ética em desenvolvimento.

Vianna (2002) comenta que, em 1983, a ONU criou a Comissão Mundial sobre Meio Ambiente e Desenvolvimento (CNMAD), que teve como objetivo elaborar um relatório sobre os problemas ambientais enfrentados por cada país e formular uma agenda global para mudanças. Assim, um dos grandes marcos para a conceituação, consolidação e popularização do termo "Desenvolvimento Sustentável" surgiu com a publicação de "Nosso Futuro Comum" (Our Common Future), também conhecido como Relatório Brundtland, em 1987, pela World Commission on Environment and Development (WCED), que de uma forma resumida diz que "o desenvolvimento sustentável é aquele que atende às necessidades do presente sem comprometer a possibilidade de as gerações futuras atenderem a suas próprias necessidades", e estabelece que a pobreza, a desigualdade social e a degradação ambiental não podem ser analisadas de maneira isolada.

Em 1991, o Programa das Nações Unidas para o Meio Ambiente (PNUMA), o Fundo Mundial para a Natureza (WWF) e a União Internacional para a Conservação da Natureza (UICN) produziram um documento conhecido por Cuidando do Planeta Terra, com nove princípios para a construção de uma sociedade sustentável:

1. Respeitar e cuidar da comunidade dos seres vivos;

2. Melhorar a qualidade de vida humana;

3. Conservar a vitalidade e a diversidade do planeta Terra;

4. Minimizar o esgotamento de recursos não renováveis;

5. Permanecer nos limites da capacidade de suporte do planeta Terra;

6. Modificar atitudes e práticas pessoais;

7. Permitir que as comunidades cuidem de seu próprio meio ambiente;

8. Gerar uma estrutura nacional para a integração de desenvolvimento e conservação;

9. Constituir uma aliança global. 


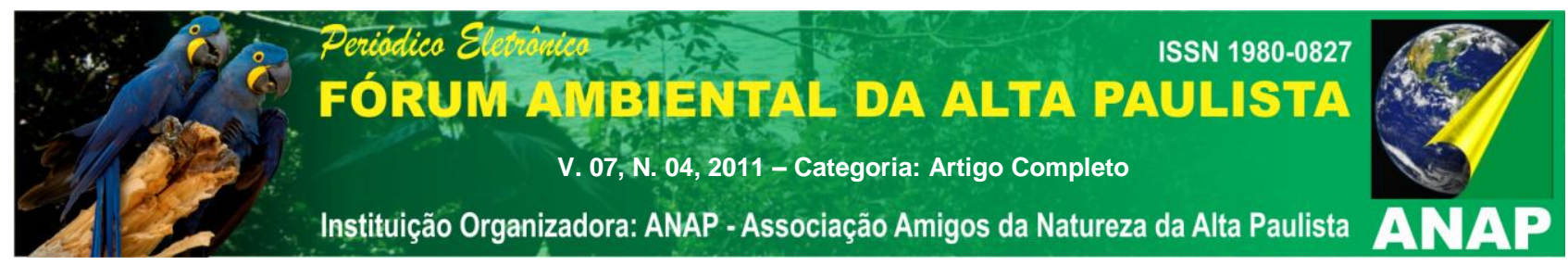

10.

Esses princípios inter-relacionados "refletem, em última análise, declarações a respeito de uma equidade mundial de desenvolvimento sustentável e de conservação da natureza, como um direito dela própria e como fato essencial para a sustentação da vida humana" (MILARÉ, 2000).

E, com o propósito de elencar estratégias para os problemas de degradação e pobreza apresentados pelo Relatório Brundtland, em 1992 na cidade do Rio de Janeiro, Brasil, uma nova Conferência foi realizada - a Conferência das Nações Unidas sobre Meio Ambiente e Desenvolvimento (CNUMAD) ${ }^{2}$, também conhecida como "Conferência da Terra" ou "Rio 92", onde se adotou na Declaração do Rio e na Agenda 21 o desenvolvimento sustentável como meta a ser buscada e respeitada por todos os países ${ }^{3}$. Foi nesta Conferência que se incorporou definitivamente o tema desenvolvimento ao meio ambiente.

Após a Rio 92, a ONU realizou novas conferências em torno da questão do desenvolvimento sustentável. Em 1996 foram realizadas a Segunda Conferência das Nações Unidas sobre Assentamentos Humanos (Habitat II), em Istambul, na Turquia, e a Conferência de Berlim Sobre Cidades Sustentáveis. Figueiredo (2000) aduz que, em ambas as conferências, "as questões urbanas e ambientais, muitas vezes tratadas separadamente, foram associadas, tendo como objetivo a obtenção de assentamentos humanos sustentáveis".

A Habitat II serviu de oportunidade para examinar os efeitos negativos dos assentamentos humanos produzidos e a capacidades destes em conseguir "os objetivos fixados em conferências anteriores realizadas pelas Nações Unidas, em especial as recomendações efetuadas pela Agenda 21" (VIANNA, 2002), e a Conferência de Berlim instituía que o chamado Desenvolvimento Sustentável era possível somente quanto "todas as pessoas tivessem a condição de direito à cidade, entendida como a garantia de participação plena na vida local, com real acesso aos bens e serviços, esses sendo gerenciados de forma a produzirem um impacto mínimo sobre o meio ambiente" (TEIXEIRA et al., 1998).

\footnotetext{
${ }^{2}$ United Nation Conference for Environment and Development.

${ }^{3}$ Princípio 4 da Declaração do Rio: Para se alcançar o desenvolvimento sustentável, a proteção do meio ambiente deve constituir parte integrante do processo de desenvolvimento e não pode ser considerada isoladamente em relação a ele.
} 


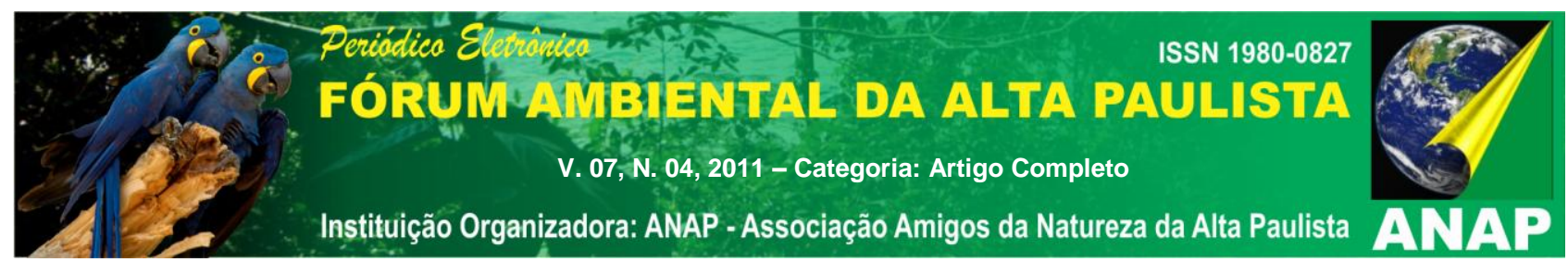

Percebe-se, contudo, que ambas as Conferências (Habitat II e de Berlim) tinham por objetivos a erradicação da pobreza, visando a necessidade de se criar uma melhor qualidade de vida nos assentamentos humanos, através da integração do desenvolvimento econômico, social e proteção ambiental.

Assim, nos últimos anos inúmeros outros eventos e documentos têm abordado a questão da sustentabilidade. No entanto, apesar de esses eventos e documentos começarem a esboçar conceitos de sustentabilidade, deve-se ter consciência da dificuldade de sua implantação, pois, além de questões técnicas, há ainda uma série de aspectos ligados à cultura, hábito e comportamento das pessoas que devem ser considerados.

\title{
2.2. SUSTENTABILIDADE: A DIFICULDADE DE SE DEFINIR
}

Definir sustentabilidade é uma tarefa complexa devido à apropriação do termo por distintas áreas de conhecimento. Lee \& Lee (apud MILANEZ, 2002) comentam que

\begin{abstract}
Apesar da expressão desenvolvimento sustentável ter sido popularizada e consolidada por ambientalistas e pessoas preocupadas com o meio ambiente, o primeiro uso do termo foi puramente econômico - desenvolvimento sustentável estritamente significa manter os negócios crescendo e avançando.
\end{abstract}

Alguns críticos consideram a expressão desenvolvimento sustentável um paradoxo, pois associam o conceito de desenvolvimento com o de crescimento, privilegiando o aspecto quantitativo. Numa direção oposta, "há os que também negaram a expressão por considerarem que a palavra desenvolvimento não deveria ser acompanhada por qualquer adjetivo ou prefixo, partindo do princípio de que se não for sustentável, não é desenvolvimento" (...) pois "a sustentabilidade não poderia ocorrer numa economia de livre mercado, com a competitividade e a necessidade de consumo cada vez maiores" (TEIXEIRA et al., 1998).

No entanto, apesar dessas e outras resistências, a expressão tem encontrado uma boa aceitação. E determinar, objetivar e aplicar o conceito de sustentabilidade passa a ser, então, foco de maior atenção. 


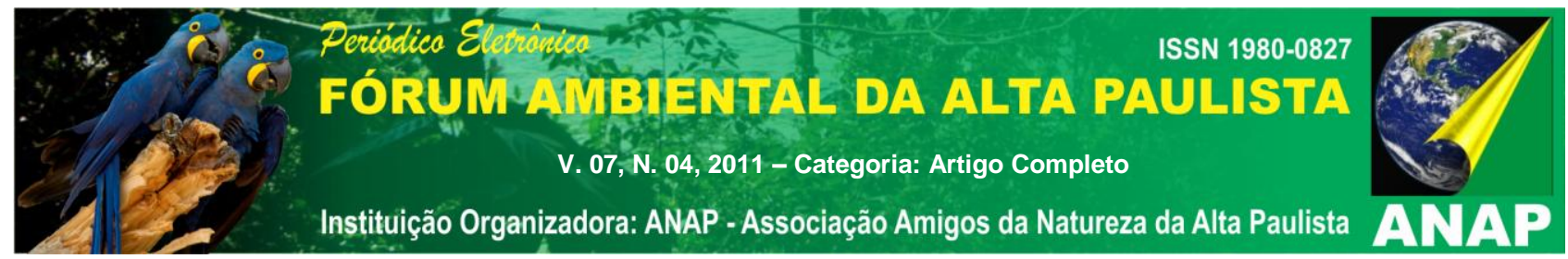

Assim, apesar de as palavras Sustentabilidade e Desenvolvimento Sustentável dificilmente terem definição precisa, "surgiram nas últimas décadas para traduzir várias idéias e preocupações relativas aos rumos das sociedades humanas" (TEIXEIRA, 2002).

\subsection{MEIO URBANO E SUSTENTABILIDADE}

Como visto anteriormente, o conceito sustentabilidade foi colocado em pauta, inicialmente, pelo movimento ambientalista, que enfatizava somente a preocupação com a primeira natureza, aquela dos espaços naturais. Posteriormente, o conceito se ampliou, passando a ser utilizado também pela segunda natureza, aquela que integra os espaços transformados pela urbanização.

Santos e Mota (2004) frisam que

O relatório Bruntland (1987) consolidou o relacionamento entre a cidade e o meio ambiente, uma tendência que vinha se afirmando desde o final da década de 1960. A Agenda 21, plano de ação da Conferência da ONU sobre o meio ambiente e desenvolvimento (1992), dá mais objetividade à questão ao estabelecer como problema ambiental a qualidade dos assentamentos humanos. A Agenda Habitat, plano de ação da Conferência da ONU sobre assentamentos humanos (1996), consagra a dimensão ambiental nas cidades e estabelece a sustentabilidade e a gestão democrática como estratégias para o enfrentamento dos problemas urbanos.

$E$, pelo fato de esses espaços estarem crescendo de forma desordenada, sua implantação acaba desrespeitando as condições do meio natural. Pippi, Afonso e Santiago (2005) comentam que a "degeneração e degradação de nossas cidades, bem como de todos seus ecossistemas" é resultado da cumulação da desorganização urbana e do aumento populacional com a falta de integração entre o meio urbano e o natural.

Já Gore (apud PIPPI, AFONSO E SANTIAGO, 2005) acredita que "o problema não é o efeito da urbanização sobre o ambiente, mas a sua relação com ela mesma, pois está faltando organização em nossas cidades". Essa falta tem desencadeado vários problemas econômicos, sociais, políticos e ambientais, tais como o crescimento urbano desarticulado, exclusão social, aumento da densidade populacional, resíduos urbanos, poluição, desmatamento, erosão, fome, violência, etc.

Os autores (PIPPI, AFONSO E SANTIAGO, 2005) ressaltam que 


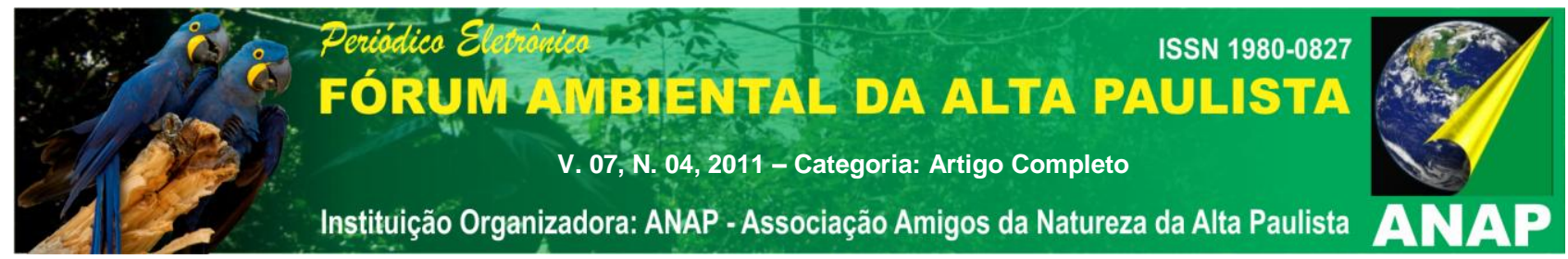

Devemos acabar com as cidades desarticuladas e formadas por camadas sociais distintas, onde a classe alta fica isolada e murada em condomínios fechados, com grades de segurança, a classe média fica esquecida e a classe baixa (favelados e invasores de terra) vive marginalizada em terras inundáveis, nas encostas e morros, longe da infra-estrutura e do alcance dos equipamentos urbanos. Os locais ocupados pela camada mais baixa acabam degradando rapidamente os recursos naturais, e conseqüentemente são os primeiros a sofrerem os efeitos de ação-reação da natureza, como erosão, enchentes, doenças, etc.

Assim, é necessário criar um ambiente urbano mais harmônico e equilibrado, para obter a sustentabilidade tanto da cidade como do ambiente natural, e uma maior qualidade de vida populacional.

Mas, para isso é necessário resgatar e conservar os bens paisagísticos combatendo crescimento urbano descontrolado e considerando os valores ambientais de cada região da cidade, além de criar princípios de conservação e reeducação social, ou seja, é necessário um planejamento adequado com enfoque na sustentabilidade.

Neste contexto, a sustentabilidade surge como uma possibilidade de enfrentamento dos problemas surgidos com a urbanização em larga escala. Conseqüentemente, como destacam Pippi, Afonso e Santiago (2005), "a cidade não deve apenas ser produzida por normas padronizadas, é preciso articular as dimensões econômicas e sociais das dimensões territoriais para que haja a gestão do solo".

Sachs (1993) vai mais além. Dividiu a sustentabilidade em cinco dimensões, segundo as quais o desenvolvimento sustentável está baseado:

- Sustentabilidade social: tem como meta a eqüidade na distribuição de rendas e bens, e a redução da distância entre os ricos e pobres;

- Sustentabilidade econômica: tem como meta alocar e gerenciar com mais eficiência os recursos e fluxos de investimentos públicos e privados;

- Sustentabilidade ecológica: tem como meta intensificar o uso potencial de recursos dos diversos ecossistemas, com o mínimo de dano; limitar o consumo de produtos que são esgotáveis ou danosos ao meio ambiente; reduzir o volume de resíduos e de poluição, por meio de conservação de energia e recursos e da reciclagem; autolimitar o consumo por parte dos países ricos e dos indivíduos; intensificar pesquisas com tecnologias ambientalmente mais adequadas; definir normas de proteção ambiental;

- Sustentabilidade espacial: tem como meta a obtenção de uma configuração rural-urbana mais equilibrada, reduzindo as concentrações excessivas de áreas metropolitanas, protegendo os ecossistemas frágeis e criando reservas para proteção da biodiversidade; promovendo a exploração agrícola e agro-silvícola com técnicas modernas, regenerativas e em escalas menores, explorando o potencial da industrialização descentralizada, acoplando novas tecnologias, e criando uma rede de reservas naturais para proteger a biodiversidade; 


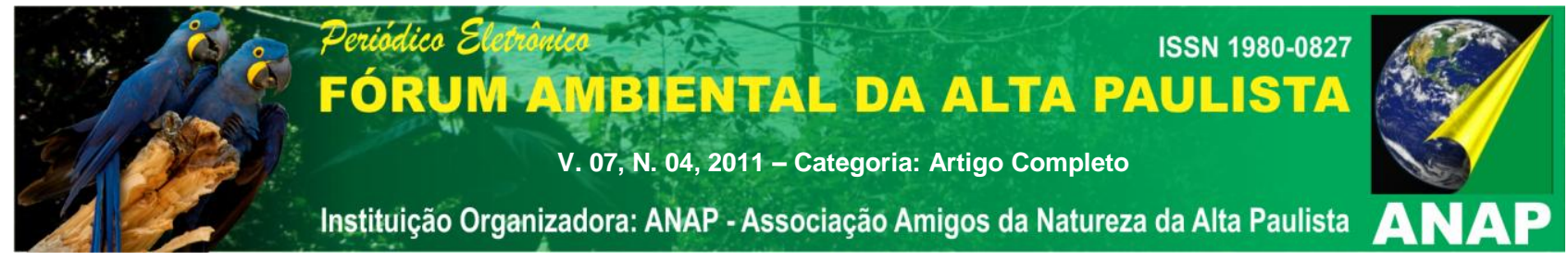

- Sustentabilidade cultural: tem como meta incluir a procura de raízes endógenas nos processos de modernização, com soluções específicas para o local, o ecossistema, a cultura e a área.

Assim, no âmbito urbano a sustentabilidade tem que visar à evolução da cidade sem esgotamento e degradação dos recursos naturais e sem exclusão social, já que o espaço urbano é formado, além da natureza e do espaço construído (edificações e infraestrutura), por vários grupos sociais.

A cidade terá sua sustentabilidade socioambiental ameaçada quando os interesses privados comprometerem os interesses sociais e coletivos. Assim, busca-se com a sustentabilidade socioambiental implementar a gestão democrática; combater as desigualdades e a exclusão social, promovendo qualidade de vida e do ambiente; e descentralizar as cidades para aproximar a urbanidade dos bairros.

No entanto, o modelo de desenvolvimento brasileiro tem causado desigualdade social, pois concentra nas mãos de poucos todos os tipos de recursos, sobrando para a imensa maioria da população uma série de mazelas, que se expressam na forma de segregação espacial em áreas de serviços públicos e infra-estrutura precários.

O trabalho e a renda estão entre os fatores cruciais para viabilizar a vida humana e proporcionar o desenvolvimento sustentável. No entanto, no Brasil a recessão econômica, juntamente com a reestruturação da produção através de modernização tecnológica e terceirização, provocou a redução da participação da mão-de-obra na produção de riqueza, gerando desemprego, além da diminuição do poder de compra do salário mínimo, que causou baixa na qualidade de vida dos brasileiros se comparada com a de outros países, fazendo-se necessária a articulação entre as políticas e legislações urbanas e ambientais.

Assim, na grande maioria das cidades brasileiras existem dois grandes problemas: a pobreza e a segregação residencial.

Quanto menos segregação residencial tiver numa cidade, maior será a chance de interação entre os grupos sociais, e menor será o preconceito. Afinal, a convivência favorece a tolerância, e a segregação realimenta a intolerância.

Melhores condições de habitação também contribuem para a diminuição dos preconceitos contra os espaços segregados, que conseqüentemente causam repercussão positiva na auto-estima coletiva. 


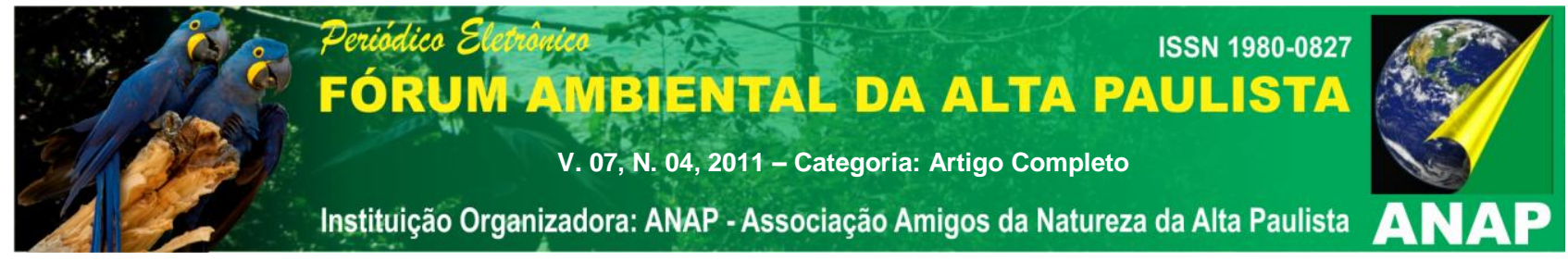

Podem ser acrescentados aos problemas da pobreza urbana e da segregação residencial, outros como a degradação ambiental. Mas é necessário derrubar o mito de que são os pobres que estão degradando o meio ambiente, pois tudo é um complexo e todos são responsáveis.

Para atingir a qualidade de vida, no entanto, é preciso, além das necessidades vitais (respirar, comer, dormir, etc), o acesso à infra-estrutura e a serviços coletivos (educação, saúde, segurança, saneamento, transporte, etc).

Equipamentos e serviços urbanos deficientes causam danos aos recursos ambientais, e mais uma vez são as parcelas mais pobres da sociedade que residem nas áreas mais mal equipadas, próximas a atividades poluidoras, que não têm acesso aos serviços de saúde de qualidade, e que sofrem as conseqüências desses danos ambientais, reforçando o vínculo entre a questão ambiental e social.

Outra questão relevante é a fundiária e habitacional, pois, como a propriedade de terra é predominantemente privada, comportamentos especulativos têm se sobreposto à função social da propriedade. A par das áreas densamente edificadas, surgem áreas vagas à espera de valorização, e os pobres acabam sendo impelidos a criar uma cidade ilegal aos redores da cidade legal, muitas vezes aproveitando áreas públicas ociosas e/ou de preservação ambiental por serem incapazes de competir no mercado formal de terra urbana. Enquanto o consumo de produtos modernos é estimulado pela mídia e facilitado pelo crédito, o mesmo não ocorre em relação à habitação. Esses moradores constroem por seus próprios meios suas moradias, sem assistência técnica ou financiamento, já que a irregularidade fundiária implica em obstáculo ao acesso ao crédito e aos programas habitacionais. As favelas, os loteamentos clandestinos e irregulares, entre outros, proliferam-se, por serem a única alternativa habitacional para a grande parte da população excluída.

As pessoas que residem nessas condições não conseguem exercer seu direito básico à habitação, que conforme a Agenda Habitat (1996) não deve ser entendida em seu sentido estrito, mas em sentido amplo, incluindo tamanho, ventilação e iluminação adequada, com boa infra-estrutura, segurança, serviços públicos como água, esgoto, coleta de resíduos sólidos (lixo), etc. 


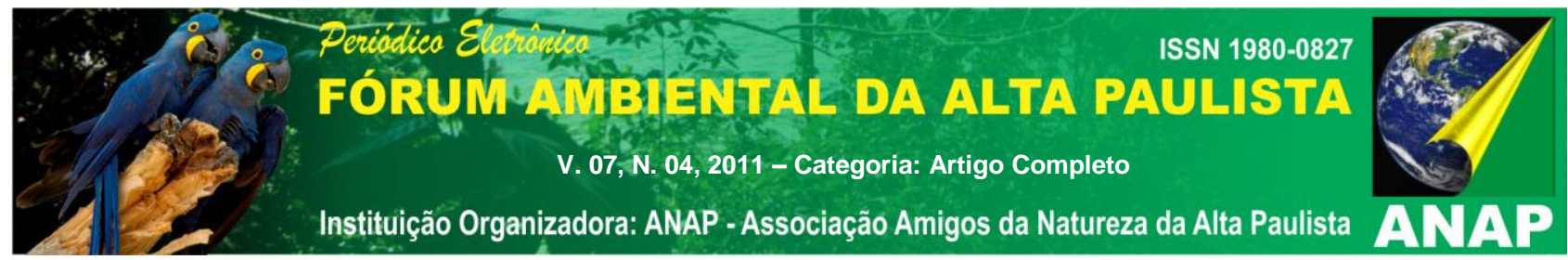

Como decorrência da dificuldade de acesso à terra urbana e da má-distribuição de renda, as cidades ilegais vêm se acentuando nas últimas décadas.

A falta de políticas de ocupação e uso do solo, bem como de sua fiscalização, a falta de infra-estrutura e de serviços de saneamento, o lançamento de efluentes industriais e sanitários sem tratamento, o despejo de resíduos sólidos (entulho e lixo) em encostas ou diretamente em cursos d'água, o desmatamento e a ocupação em margens e encostas de proteção ambiental, entre outras atividades, causam inúmeros problemas, tais como poluição e assoreamento dos cursos d'água, diminuição de áreas cobertas por vegetação, propícias à infiltração pluvial, paisagens degradadas, zonas sujeitas a inundações periódicas, entre outros.

No entanto, a população não atendida ou atendida em condições precárias localiza-se basicamente nas áreas periféricas e faveladas das cidades, onde a falta de saneamento ambiental é causa de $80 \%$ das doenças e $65 \%$ das internações hospitalares, causando inclusive morte.

Assim, esses e outros problemas urbanos vão aumentando enquanto os problemas como pobreza e segregação não são resolvidos.

A ineficácia e a inadequação dos instrumentos de planejamento e gestão urbana contribuem para o processo de segregação espacial dos segmentos mais pobres da população. Assim, as estratégias de administração urbana de forma tradicional devem ser objetos de reformulação e aperfeiçoamento porque não satisfazem as reais necessidades da população da cidade.

O Estado, tradicional promotor de segregação residencial, ao invés de investir diretamente nas áreas residenciais das cidades e estabelecer estímulos e zoneamentos e outras normas que evitem a segregação, atua como agente repressor consolidando-as.

Uma cidade marcada pela desigualdade social e pela exclusão territorial não é capaz de produzir um desenvolvimento sustentável.

Se uma cidade produz mais e mais riqueza, mas as disparidades econômicas no seio de sua população aumentam; se a riqueza produzida e o crescimento da cidade se fazem às custas da destruição da natureza e do patrimônio histórico; se à conta da modernização surgem níveis cada vez mais intoleráveis de poluição, estresse e congestionamento, não se pode falar em desenvolvimento. 


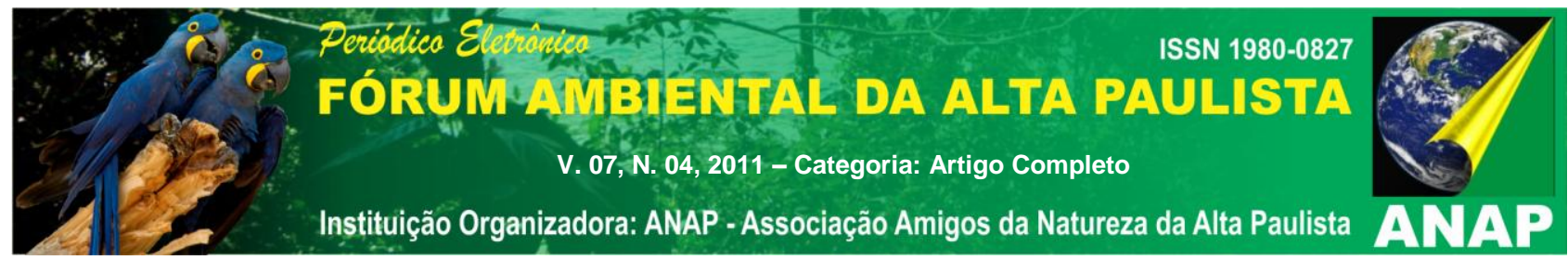

Assim, cabe ao administrador municipal promover um adequado ordenamento territorial, mediante planejamento e controle do uso, do parcelamento e da ocupação do solo; criar política visando ordenar o pleno desenvolvimento das funções sociais da cidade e da propriedade urbana, garantindo o bem-estar de seus habitantes.

No mais, o município, com base no desenvolvimento sustentável, deve apresentar uma organização do desenvolvimento urbano de modo a romper com a lógica da exclusão e segregação social; deve ter como meta efetivar a cidadania, eliminar a pobreza e o apartheid social.

O plano diretor também é um instrumento de planejamento participativo, pois a gestão democrática é condição essencial para os objetivos da política urbana.

Para que a propriedade urbana cumpra sua função social, ela deve responder às exigências fundamentais de ordenação da cidade expressas no plano diretor. Tais exigências dizem respeito à busca de melhor adequação do solo da propriedade e à responsável utilização dos recursos naturais, garantindo a preservação de meio ambiente urbano.

Mas, "quando o crescimento urbano não é acompanhado por aumento e distribuição eqüitativa dos investimentos em infra-estrutura e democratização do acesso aos serviços públicos, as desigualdades socioespaciais são geradas ou acentuadas". (COELHO, 2004).

$\mathrm{Na}$ elaboração de políticas públicas, não se pode ignorar que existe uma diversidade de formas sociais. Então, o principal desafio das cidades é criar condições que assegurem a qualidade de vida considerada aceitável, não interferindo no meio ambiente do seu entorno e agindo preventivamente para evitar impactos e depredações. Mas, enquanto a população de baixa renda não tiver acesso à moradia, transporte público, saneamento, cultura, lazer, segurança, educação, saúde e trabalho digno, a cidade não estará atendendo sua função social e, conseqüentemente, o seu desenvolvimento socioambiental.

Assim, Santos e Mota (2004) aduzem que a sustentabilidade aparece

Como uma possibilidade de enfrentamento dos problemas que vêm se acumulando a partir da urbanização em larga escala e que foram acentuados com a expansão acelerada dos espaços nos quais assentamentos humanos têm se estruturado com base em um modelo 


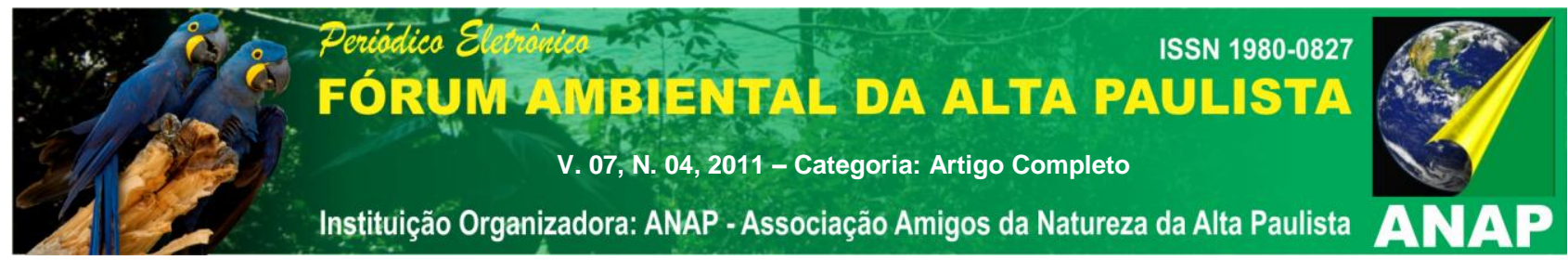

que exaure os recursos naturais, distribui desigualmente os recursos ambientais e privilegia de forma distinta os recursos humanos.

\section{3 - CONCLUSÃO}

Até a década de setenta, o conceito de desenvolvimento econômico era conflitante com os princípios de conservação ambiental. Atualmente, esta visão vem sendo substituída pela idéia de que o desenvolvimento e a conservação ambiental não são excludentes, já que a. sustentabilidade evidencia a importância da questão ambiental na construção de um modelo democrático de desenvolvimento.

No entanto, a sustentabilidade do meio urbano não se atinge de modo harmônico devido aos interesses, por vezes antagônicos entre nações ricas e pobres. Assim, o sistema deve ser entendido como um processo de mudança no qual a exploração dos recursos, a orientação dos investimentos, os rumos do desenvolvimento tecnológico e as mudanças institucionais estejam de acordo com as necessidades atuais e futuras. Não é um processo fácil, pois escolhas difíceis terão de ser feitas. Em última análise o desenvolvimento sustentável depende do empenho político das nações, principalmente das mais desenvolvidas.

Então, é preciso abandonar antes de mais nada a idéia de que há um antagonismo entre a Natureza e o Homem. A discussão deverá ser sobre os motivos que leva o Homem, querendo o seu bem estar, a entender os recursos naturais como uma utilidade para o seu conforto.

A discussão do problema não pode estar impregnada por uma forte ideologia contrária ao progresso tecnológico, mas sim até que ponto é possível conciliar a defesa da natureza com a utilização dos recursos que oferece.

\section{BIBLIOGRAFIA}

ACSELRAD, Henri. Discurso da sustentabilidade urbana. Disponível em: <http://www.brasilsustentavel.org.br/downloads.htm>. Data de acesso: 24 de abr. 2005. 


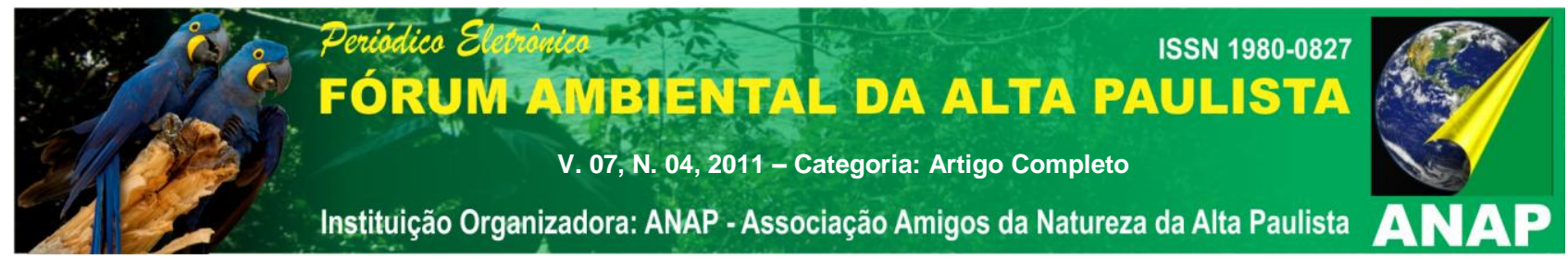

ACSELRAD, Henri; LEROY, Jean-Pierre. Novas premissas da sustentabilidade democrática. Disponível em: <http://www.brasilsustentavel.org.br/downloads.htm>. Data de acesso: 24 de abr. 2005.

BREMER, Ulisses Franz. Rumo às cidades sustentáveis. Disponível em: <http://www.agirazul.com.br/nat/cidades.htm>. Data de acesso: 03 de dez. 2004.

FREITAS, José Carlos de. O Estatuto da Cidade e o equilíbrio do espaço urbano. Disponível em: <http://www.mp.sp.gov.br>. Data de acesso: 12 de nov. 2004.

GRAZIA, Grazia de; QUEIROZ, Leda Lúcia R. F. A sustentabilidade no modelo urbano brasileiro: um desafio. Disponível em: <http://www.brasilsustentavel.org.br/downloads.htm>. Data de acesso: 24 de abr. 2005.

GRAZIA, Grazia de; SANTOS, Alexandre Mello; MOTTA, Athayde. Estratégia para a construção da sustentabilidade urbana. Disponível em: <http://www.brasilsustentavel.org.br/downloads.htm>. Data de acesso: 24 de abr. 2005.

COELHO, Maria Célia Nunes. Impactos Ambientais em áreas urbanas - teorias, conceitos e métodos de pesquisa. In: GUERRA, Antonio José Teixeira; CUNHA, Sandra Baptista da (orgs). Impactos ambientais urbanos no Brasil. Rio de Janeiro: Editora Bertrand, 2004.

FOLADORI, Guillermo. MANOEL, Marise (trad.). Limites do Desenvolvimento Sustentável. São Paulo: Imprensa Oficial, 2001.

OLIVEIRA, Isabel Cristina Eiras de. Estatuto da cidade: para aprender. Rio de Janeiro: IBAM/DUMA, 2001.

ORLANDI NETO, Narciso. Regularização do parcelamento do solo. In: FREITAS, José Carlos de (coord.). Temas de Direito Urbanístico 2. São Paulo: CAOHURB, 2000, p. 353-364.

PIPPI, Luis Guilherme Aita; AFONSO, Sonia; SANTIAGO, Aline. A aplicação da sustentabilidade no meio urbano. Disponível em: <http://www.arq.ufsc.br/ soniaa/sonia/Guilherme\%20ENECS\%202003.pdf>.Data de acesso: 24 de abr. 2005.

RHEINGANTZ, Eduardo. A megalópole da periferia. Temas de Direito Urbanístico 2. São Paulo: CAOHURB, 2000, p. 161-167.

ROCHA, Júlio Cesar de Sá da. Considerações jurídicas sobre a função ambiental da cidade. Revista de Direito Ambiental. São Paulo: n. 14, p. 103-112, abril a junho 1999.

ROCHA, Vera Lúcia da. Estudo da estrutura urbana e análise dos problemas ambientais da cidade de Iguape-SP como subsídio ao Plano Diretor do Município. 1999. 84f. Dissertação (Mestrado em Ciência da Engenharia Ambiental) - Crhea/EESC, Universidade de São Paulo, São Carlos. 1999.

SÁ, Elida; BRITO, Isa. O planejamento como instrumento da construção da cidadania. Revista de Direito Ambiental. São Paulo: n. 7, p. 34-53, julho a setembro 1997.

SACHS, Ignacy. Estratégias de transição para o século XXI. In: BURSZTYN, Marcel (org.). Para pensar o desenvolvimento sustentável. São Paulo: Editora Brasiliense 


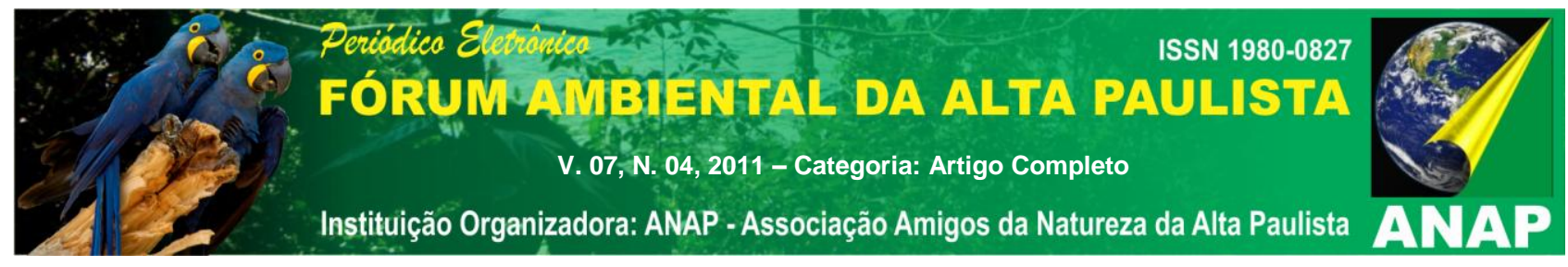

SANTOS, Alexandre Mello; MOTTA, Athayde. Desafio para a sustentabilidade no espaço urbano brasileiro. Disponível em: <http://www.brasilsustentavel.org.br/downloads.htm>. Data de acesso: 24 de abr. 2005.

SANTOS, Marcus Vinícius Monteiro dos. Loteamentos irregulares e clandestinos - a improbidade administrativa decorrente da omissão dos agentes públicos no seu dever de fiscalização. In: FREITAS, José Carlos de (coord.). Temas de Direito Urbanístico 2. São Paulo: CAOHURB, 2000, p. 241-253.

SILVA, Sandra Regina Mota. Indicadores de sustentabilidade urbana: as perspectivas e as limitações da operacionalização de um referencial sustentável. 2000. Dissertação (Mestrado em Engenharia Urbana) - Departamento de Engenharia Urbana, Universidade Federal de São Carlos, São Carlos. 2000.

----- Indicadores de sustentabilidade urbana. 2000. Disponível em: <http://www.ufscar.br/ ursus/projetos/indicadores.htm>. Data de acesso: 19 de set. 2004.

Proposição de princípios básicos para a sustentabilidade. Disponível em: <http://www.ufscar.br/ ursus/projetos/sustentabilidade.htm>.Data de acesso: 19 de set. 2004.

SOUZA, Marcelo Lopes de. ABC do desenvolvimento urbano. Rio de Janeiro: Bertrand Brasil, 2003.

VIANNA, Ana Vivian Nascimento. Análise de sustentabilidade ecológica de projetos urbanos. Avaliação do método Pesmu aplicado a fundo de vale em Ribeirão Preto/SP. 2002. Dissertação (Mestrado em Engenharia Urbana) - Departamento de Engenharia Urbana, Universidade Federal de São Carlos, São Carlos. 2002. 